\title{
Gender and Overconfidence: Effects of Context, Gendered Stereotypes, and Peer Group
}

\author{
Niklas Jakobsson ${ }^{1}$, Minna Levin ${ }^{2}$, Andreas Kotsadam ${ }^{3}$ \\ ${ }^{1}$ Norwegian Social Research (NOVA), Oslo, Norway \\ ${ }^{2}$ Schools for the Future, San Salvador, El Salvador \\ ${ }^{3}$ Norwegian Social Research (NOVA), Oslo, Norway \\ Email: niklas.jakobsson@nova.no,minna@schoolsforthefuture.org, andreas.kotsadam@nova.no
}

Received February $6^{\text {th }}$, 2013; revised March $10^{\text {th }}, 2013$; accepted March $18^{\text {th }}, 2013$

\begin{abstract}
Copyright (C) 2013 Niklas Jakobsson et al. This is an open access article distributed under the Creative Commons Attribution License, which permits unrestricted use, distribution, and reproduction in any medium, provided the original work is properly cited.
\end{abstract}

\begin{abstract}
Research on Swedish school children has found that boys tend to be overconfident about their grades in mathematics, while girls tend to be underconfident. We find similar results for El Salvadorian children. Mathematics is considered a masculine task and we show that these findings do not carry over to a gender neutral task (social science), where both sexes tend to be overconfident. We find that girls in a single-sex school are more underconfident in their mathematics abilities than girls in a co-ed school, which may suggest that gender stereotypes become reinforced in single-sex environments.
\end{abstract}

Keywords: Gender, Overconfidence, Peer Group, Stereotype

\section{Introduction}

Previous research indicates that people are generally overconfident in diverse areas as car-driving, investment decisions, entrepreneurial behavior, running, stock market forecasts, answering quiz questions, and solving fictitious mathematical problems (e.g., Beckmann \& Menkhoff, 2008; Croson \& Gneezy, 2009; Deaves, 2010; Koellinger et al., 2007; Svensson, 1981). And while both men and women are overconfident, men are generally more so than women (Estes \& Jinos, 1988; Fellner \& Maciejovsky, 2007; Soll \& Klayman, 2004; Niederle \& Vesterlund, 2007). Dahlbom et al. (2010) find that Swedish schoolboys tend to be overconfident with respect to their mathematics performance, while girls tend to be underconfident.

Differences in confidence are likely to translate into differences in outcomes, educational choices, and labor market segregation. Dahlbom et al. (2010) argue that gender differences in confidence may perpetuate segregated labor markets, by means of self-selection. An indirect effect of confidence differences may also be at work via competition decisions and performance. Niederle and Vesterlund (2007) show that male overconfidence is a key factor in explaining gender differences in willingness to compete and in selection of compensation schemes, and they argue that this may help explain the underrepresentation of women in top-level company positions. Palomino et al. (2010) model how male overconfidence leads to gender wage differences even with equal productivity and equal compensation policies since more men apply for high paid jobs and exert more effort.

In this paper, we study the gender gap in confidence among school children. For comparability with Dahlbom et al. (2010), we conduct a study with a similar design, i.e., we ask students about their expected test results before a test and compare with the actual results, yet our study extends the results in Dahlbom et al. (2010) along a number of important dimensions.

First of all, our design allows us to test for peer group effects by including not only a mixed school but also an all-girls school. Several studies have shown that men often outperform women in competitions, even when they perform equally well in a non-competitive setting (e.g., Gneezy et al., 2003; Gneezy \& Rustichini, 2004). Niederle \& Vesterlund (2007) show that there is a gender difference in selection into competition, but the response to competition and the selection into it may, however, vary with the task used or with the gender composition of the groups (Croson \& Gneezy, 2009). Ortmann and Tichy (1999) look at prisoner's dilemma games and find men to act the same in mixed groups as in men-only groups. Women, on the other hand, were more cooperative in the mixed-sex groups. Gneezy and Rustichini (2004) find that competition enhances the performance of males but not of females in a short distance running race in an Israeli elementary school. The gender composition also had an effect: When girls competed against girls, their performance was worse compared to when running alone. In the mixed races did the girls performed less well than when running alone but better than when competing against only girls. For boys, there was no statistically significant difference between the performance in mixed races and boys-only races and their performance was better compared to when running alone. Booth and Nolen (2012a, 2012b) find that girls in single-sex schools compete more and are less risk averse than girls from co-ed schools in Great Britain, suggesting that these traits are not only in inherent but may also depend on the social setting. Our study is the first to test if the gender differences in confidence varies between single-sex and mixed sex environments.

Secondly, in addition to performance in mathematics, we also consider overconfidence regarding performance in the 
social sciences. This addition is important since, as Niederle and Vesterlund (2007) point out, differences in overconfidence are task dependent and gender differences have generally been found in masculine tasks. Meier-Pesti and Penz (2008) argue that risk taking is perceived as a masculine characteristic and that previous results on the gender differences in risk taking stems from this fact. They move on to show that gender differences in risk taking decreased once they controlled for masculinity and that activating the cognitive schema of male sex role stereotype by gender priming increased risk taking. Lundeberg et al. (1994) find men to be more confident than women regarding exam questions related to math, but not regarding exam questions related to learning, memory, or experimental design. Beyer (1990) and Beyer and Bowden (1997) show that gender differences in the accuracy of self-perceptions are significant for masculine tasks (where men are generally overconfident and women underconfident), while no differences were found for feminine or neutral tasks. Finally, Günther et al. (2010) show that women are less competitive than men in male tasks, but more competitive in the studied female task; no difference is found for gender neutral tasks. Hence, it is crucial to distinguish between masculine and non-masculine tasks. If both sexes agree that members of one sex are better at a task, it is said to be gender typed. It is important to note that the categorization need not be supported by facts, only by stereotypes, so that when Gneezy and Rustichini (2004) contend that there is no gender difference in performance with respect to running short races, there might still be stereotypical perceptions of the task nonetheless. Mathematics is a typical example of a masculine-typed task (e.g., Beyer, 1990; Beyer \& Bowden, 1997; Janman, 1987; Mura, 1987; Tiedemann, 2000), that is not supported by actual differences in results at lower levels or at young ages (Dahlbom et al., 2010; Niederle \& Vesterlund, 2007; our data also shows that girls outperform boys on the mathematics test). Social science, on the other hand, is generally considered gender neutral and by including it in addition to mathematics in our study, we are able to investigate whether the results in Dahlbom et al. (2010) generalize to non-masculine tasks.

Finally, by following the design of Dahlbom et al. (2010) but applying it to another country, we are able to test for gender differences in overconfidence across countries. Previous confidence research has been more occupied with individual rather than social psychology, and we aim to fill this gap by introducing context as a crucial component of the analysis. Since we are looking specifically at gender differences, the societal level of gender equality is likely to be important, especially if gender roles are partly a product of childhood socialization. For instance, the gender differences between Israeli boys and girls in running race performance found by Gneezy and Rustichini (2004) were not found in a similar study on Swedish schoolchildren conducted by Dreber et al. (2011), and JohanssonStenman and Nordblom (2010) find no gender differences in overconfidence in an economics exam in Sweden. Guiso et al. (2008) studied gender differences in mathematics and reading test scores across countries. On average, girls performed worse on the math test and better on the reading test than boys, yet the results vary by country. In particular, in countries with greater gender equality (as measured by the World Economic Forum's Gender Gap Index), the differences in mathematics disappear or even get reversed while the gap in reading increases. Our study is conducted in El Salvador, a less gender equal country than
Sweden (which was used by Dahlbom et al., 2010). The Global Gender Gap Report 2012 ranks Sweden as the fourth most gender equal country in the world; El Salvador ranks 94th (Hausmann, Tyson, \& Zahidi, 2012).

Croson and Gneezy (2009) review economic and psychological research on gender differences in experiments and find that women's social preferences are more context specific than those of men, and a potential reason for this is said to be women's higher sensitivity to social cues. Recent experimental research has highlighted the importance of social structure. Gneezy et al. (2009) contrast the results from the same experiment across cultures. They look at the patriarchal Maasai society in Tanzania and a matrilineal Khasi society (offspring belong to the mother's group after birth) in India and find that men in the patriarchal society choose to compete twice as often as women, whereas women choose to compete more often than men in the matrilineal society. In a similar vein, Andersen et al. (2008) conducted a public goods experiment in three different Indian societies, one matrilineal and two patriarchal, and found that fewer individuals free-ride and more is spent on the public good in the matrilineal society. By following the design used in Dahlbom et al. (2010), we can examine the gender differences in math confidence between countries and hence shed light on the role of different contexts.

One aim of this study is therefore to find out whether Dahlbom et al.’s (2010) results are generalizable to youth in less gender equal societies. Another aim is to investigate differences between the highly gendered topic of mathematics and the less gendered topic of social science. Most importantly, though, we aim to find out whether girls in single-sex schools differ from girls in co-ed schools in terms of confidence, as found regarding risk and competition behavior in Great Britain (Booth \& Nolan, 2012a, 2012b).

\section{Data Description and Method}

Our sample consists of 129 students aged 15 - 16 from two schools in Santa Tecla in El Salvador. In total, 66 students come from a co-ed school (34 boys and 32 girls) and 63 students come from an all-girls school. Both schools are public schools and free of charge. All children come from a similar social background (poor) and all parents can register their kids at either school.

The students were asked what grades (from 1 to 10 , where 10 is the highest) they expected to get on two subsequent testsone in mathematics and one in social science. What we here call social science is a subject called "sociales" which is a combination of social science and language. The questions were "What grade do you expect to get on the upcoming exam in mathematics?" and "What grade do you expect to get on the upcoming exam in social science?” We also have the actual test results for each student.

For statistical testing we will use the Wilcoxon signed rank sum test, which is a non-parametric version of a paired samples t-test. We use this test statistic since we use ordinal and not necessarily normally distributed data.

\section{Overconfidence in Math and Social Science}

We consider the differences between boys and girls for the total sample and compare them to those found by Dahlbom et al. (2010). Table 1 presents the mean beliefs and results for the 
Table 1.

Mean beliefs and actual results in the total sample.

\begin{tabular}{cccccc}
\hline & Belief math & Result math & $\begin{array}{c}\text { Belief social } \\
\text { science }\end{array}$ & $\begin{array}{c}\text { Result social } \\
\text { science }\end{array}$ & Obs. \\
\hline Total & 7.000 & 7.132 & 7.938 & 7.109 & 129 \\
& $(1.811)$ & $(1.665)$ & $(1.230)$ & $(1.830)$ & \\
Girls & 7.000 & 7.526 & 7.989 & 7.484 & 95 \\
& $(1.919)$ & $(1.597)$ & $(1.276)$ & $(1.694)$ & \\
Boys & 7.000 & 6.029 & 7.794 & 6.059 & 34 \\
\hline
\end{tabular}

Note: Mean values and standard deviations in parentheses.

total sample, for boys and for girls, respectively. Expected grades differ from actual grades. Both girls and boys overestimate their social science performance (statistically significant at the 5 percent level for girls and the 1 percent level for boys, using a Wilcoxon signed rank test). Throughout the paper, the reported statistical significance refers to Wilcoxon signed rank tests unless stated otherwise. Regarding math, girls underestimate their performance (statistically significant at the 10 percent level), while boys overestimate theirs (statistically significant at the 1 percent level). The difference between girls and boys in confidence is also statistically significant (at the 1 percent level in a Wilcoxon rank sum test) for both mathematics and social science.

Regarding mathematics performance, we thereby find the same results as the Swedish study (Dahlbom et al., 2010), where girls tended to be underconfident and boys overconfident. With respect to social science, on the other hand, both girls and boys are generally overconfident, but boys more so than girls. This is in line with research on confidence in other areas of life (e.g., Estes \& Jinos, 1988; Soll \& Klayman, 2004; Niederle \& Vesterlund, 2007). Thus, the results found in Dahlbom et al. (2010) for mathematics seem to generalize even to less gender equal countries like El Salvador. It is also interesting to note that not only do the results differ by task, the direction of confidence bias is even reversed for girls; i.e., girls are overconfident in the gender neutral typed task, although less so than men, while they are underconfident in the masculine typed task.

\section{Mixed Schools and Single-Sex Schools}

Earlier research suggests that differences in confidence between girls and boys may depend on peer groups. Booth and Nolen (2012a, 2012b) find that girls in single-sex schools compete more and are less risk averse than girls from mixed schools. An important question is whether the gendered peer group effect is salient also for confidence, and whether their result generalizes to outside Great Britain. Thus, we will investigate whether there are any differences between girls from single-sex schools and girls from mixed schools. More specifically, if the results regarding risk aversion and competition translate directly to confidence, we would expect to find that girls in the all-girls school are more overconfident with respect to social science and less underconfident with respect to math, than are girls in the co-ed school. On the other hand, if the gender typedness of a task gets reinforced in single-sex environments, we may find that girls in the all-girls school are more underconfident regarding their mathematics abilities than are girls in the mixed school.

Table 2 presents the mean expectations and results for all
Table 2.

Mean beliefs and actual results for girls in the mixed and single-sex school.

\begin{tabular}{cccccc}
\hline & Belief math & Result math & $\begin{array}{c}\text { Belief social } \\
\text { science }\end{array}$ & $\begin{array}{c}\text { Result social } \\
\text { science }\end{array}$ & Obs. \\
\hline Girls, total & 7.000 & 7.526 & 7.989 & 7.484 & 95 \\
& $(1.919)$ & $(1.597)$ & $(1.276)$ & $(1.694)$ & \\
Mixed & 7.188 & 5.969 & 7.938 & 6.906 & 32 \\
school & $(1.857)$ & $(1.257)$ & $(1.294)$ & $(1.532)$ & \\
Single-sex & 6.905 & 8.317 & 8.016 & 7.778 & 63 \\
school & $(1.957)$ & $(1.090)$ & $(1.276)$ & $(1.708)$ & \\
\hline
\end{tabular}

Note: Mean values and standard deviation in parentheses.

girls, girls in the mixed school, and girls in the single-sex school, respectively. The results shown in the first row are the ones presented also in Table 1. In the second row, the results for girls in mixed school are presented. These girls are overconfident, not only regarding social science, but also regarding mathematics (statistically significant at the 1 percent level for both social science and math). Girls in the single-sex school are underconfident regarding their math performance (statistically significant at the 1 percent level), while regarding their social science abilities, they believe they will get a slightly higher score than they actually do, although this difference is not statistically significant. The difference between girls from the two types of schools is statistically significant at 1 percent for math performance and at 5 percent for social science performance (using the Wilcoxon rank sum test).

Thus, our results indicate that girls from the single-sex school are less like boys in terms of confidence, as compared to girls from mixed schools. This is contrary to the results we would have obtained had the results regarding competition and risk taking (Booth \& Nolen, 2012a, 2012b), where girls in single-sex schools are more similar to boys than are girls in mixed schools, been directly transferable. Since we find that girls in the single-sex school tend to be underconfident while those in mixed schools tend to be overconfident in the masculine typed task, the results may suggest that single sex environments reinforce stereotypes of gender typedness.

\section{Discussion}

Confidence has been widely studied in psychology and economics. Confidence is important for aspirations, motivation, and preferences for challenging tasks, and may affect career choices and education (Beyer \& Bowden, 1997; Dahlbom et al., 2010). Previous research has found that people generally are overconfident in diverse areas as car-driving, investment decisions, running, stock market forecasts, answering quiz questions, and solving fictitious mathematical problems. And while both men and women are overconfident, men are generally more so than women. Previous confidence research has been more occupied with individual rather than social psychology, and we aim to fill this gap by introducing context as a crucial component of the analysis. We conducted a survey where high school students from a co-ed school and an all-girls school were asked what grades they thought they would get on two subsequent tests-one in mathematics and one in social science. Their expectations were then compared to their actual grades.

In line with the Swedish results from Dahlbom et al. (2010), this article shows that boys tend to be overconfident in their 
mathematics skills, while girls are underconfident. The results regarding mathematics therefore seem to be generalizable across cultures. Mathematics is regarded as a masculine typed task while social science is regarded as gender neutral. The present study shows that both girls and boys are overconfident in their social science abilities, but girls less so than boys. We thereby conclude that gender typedness of task does matter. This is especially true for girls, for whom the confidence bias is reversed across tasks. That is, girls are overconfident in the gender neutral typed task, although less so than boys, while they are underconfident in the masculine typed task. Furthermore, we show that girls from the all-girls school are more underconfident in their mathematics abilities than girls in the co-ed school. This contrasts results found for competition and risk taking (Booth \& Nolen, 2012a, 2012b), where girls in single-sex schools are more competitive and risk taking than are girls in mixed schools. Our finding that girls from the single-sex school are underconfident while mixed school girls are overconfident in the masculine typed task may suggest that single-sex environments reinforce stereotypes of gender typedness. On the other hand, since girls from the single-sex school are less confident than girls in the mixed school in both tasks, it may be a matter of an effect on self-confidence in general.

Thus, single sex schooling seems to affect self-confidence differently than it affects risk taking and competitive behavior. It may, however, also be the case that the effects differ among countries. The results may also be driven by selection into schools based on unobserved characteristics. Both schools are public schools (free of charge) in Santa Tecla in El Salvador. All children come from very poor conditions and parents are free to register their kids at either school. We may have a problem if attendance in one of the schools is correlated with confidence. If so, we cannot identify the effect of being in an all-girls school or a co-ed school. Another potential problem is that the children in the co-ed school answered the confidence questions the day before their tests, while the children in the all-girls school answered the questions two weeks before the test. If for example time inconsistency is of importance, this may be what drives the results. Furthermore, it is interesting to note that the differences, especially between the different schools, are driven by differences in results rather than differences in expectations. Taken together with the result in Hoxby (2000) that both males and females perform better in mathematics in classes with more females, this may imply that sin-gle-sex environments affect results without affecting confidence. More research, from different contexts, is definitely warranted to shed light on these issues.

\section{REFERENCES}

Andersen, S., Bulte, E., Gneezy, U., \& List, J. (2008). Do women supply more public goods than men? Preliminary experimental evidence from matrilineal and patriarchal societies. American Economic Review, 98, 376-381. doi:10.1257/aer.98.2.376

Beckmann, D., \& Menkhoff, L. (2008). Will women be women? Analyzing the gender difference among financial experts. Kyklos, 61, 364-384. doi:10.1111/j.1467-6435.2008.00406.x

Beyer, S. (1990). Gender differences in the accuracy of self-evaluations of performance. Journal of Personality and Social Psychology, 59, 960-970. doi:10.1037/0022-3514.59.5.960

Beyer, S., \& Bowden, E. (1997). Gender differences in self-perceptions: Convergent evidence from three measures of accuracy and bias. Personality and Social Psychology Bulletin, 23, 157-172. doi:10.1177/0146167297232005

Booth, A. L., \& Nolen, P. (2012a). Gender differences in risk behaviour: Does nurture matter? Economic Journal, 122, F56-F78. doi:10.1111/j.1468-0297.2011.02480.x

Booth, A. L., \& Nolen, P. (2012b). Choosing to compete: How different are girls and boys? Journal of Economic Behavior \& Organization, 81, 542-555. doi:10.1016/j.jebo.2011.07.018

Campbell, A. (2002). A mind of her own: The evolutionary psychology of women. Oxford: Oxford University Press. doi:10.1093/acprof:oso/9780198504986.001.0001

Croson, R., \& Gneezy, U. (2009). Gender differences in preferences. Journal of Economic Literature, 47, 448-474. doi:10.1257/jel.47.2.448

Dahlbom, L., Jakobsson, A., Jakobsson, N., \& Kotsadam, A. (2010). Gender and overconfidence: Are girls really overconfident? Applied Economics Letters, 18, 325-327. doi:10.1080/13504851003670668

Deaves, R., Lüders, E., \& Schröder, M. (2010). The dynamics of overconfidence: Evidence from stock market forecasters. Journal of Economic Behavior and Organization, 17, 402-412. doi:10.1016/j.jebo.2010.05.001

Dreber, A., von Essen, E., \& Ranehill, E. (2011). Outrunning the gender gap: Boys and girls compete equally. Experimental Economics, 14, 567-582. doi:10.1007/s10683-011-9282-8

Eckel, C., \& Grossman, P. (2008). Differences in the economic decisions of men and women: Experimental evidence. In C. Plott, \& V. Smith (Eds.), Handbook of experimental results (Vol. 1, Chapter 57, pp. 509-519). New York: Elsevier. doi:10.1016/S1574-0722(07)00057-1

Estes, R., \& Jinos, H. (1988). The gender gap on Wall Street: An empirical analysis of confidence in investment decision making. Journal of Psychology, 122, 577-590. doi:10.1080/00223980.1988.9915532

Fellner, G., \& Maciejovsky, B. (2007). Risk attitude and market behavior: Evidence from experimental asset markets. Journal of Economic Psychology, 28, 338-350. doi:10.1016/j.joep.2007.01.006

Gneezy, U., Niederle, M., \& Rustichini, A. (2003). Performance in competitive environments: Gender differences. The Quarterly Journal of Economics, 118, 1049-1074. doi:10.1162/00335530360698496

Gneezy, U., \& Rustichini, A. (2004). Gender and competition at a young age. American Economic Review, 94, 377-381. doi:10.1257/0002828041301821

Gneezy, U., Leonard, K., \& List, J. (2006). Gender differences in competition: Evidence from a matrilineal and a patriarchal society. Econometrica, 77, 1637-1664. doi:10.1126/science.1154094

Guiso, L., Monte, F., Sapienza, P., \& Zingales, L. (2008). Culture, gender, and math. Science, 320, 1164-1165. doi:10.1016/j.jebo.2010.05.003

Günther, C., Ekinci, A., Schwieren, C., \& Strobel, M. (2010). Women can't jump?-An experiment on competitive attitudes and stereotype threat. Journal of Economic Behavior and Organization, 75, 395401.

Hausmann, R., Tyson, L. D., \& Zahidi, S. (2012). The global gender gap report 2012. http://www3.weforum.org/docs/WEF_GenderGap_Report_2012.pdf

Hoxby, C. (2000). Peer effects in the classroom: Learning from gender and race variation. NBER Working Paper 7867.

Jakobsson, N., \& Kotsadam, A. (2010). Do attitudes toward gender equality really differ between Norway and Sweden? Journal of European Social Policy, 20, 142-159. doi: $10.1177 / 0958928709358790$

Johansson-Stenman, O., \& Nordblom, K. (2010). Are men really more overconfident than women? A natural field Experiment on exam behavior. Working Papers in Economics No. 461, University of Gothenburg.

Koellinger, P., Minniti, M., \& Schade, C. (2007). "I think I can, I think I can": Overconfidence and entrepreneurial behaviour. Journal of Economic Psychology, 28, 502-527. doi:10.1016/j.joep.2006.11.002

Lundberg, M., Fox, P. \& Punchchar, J. (1994). Highly confident but wrong: Gender differences and similarities in confidence judgements. Journal of Educational Psychology, 86, 114-121.

doi:10.1037/0022-0663.86.1.114 


\section{N. JAKOBSSON ET AL.}

Meier-Pesti, K., \& Penz, E. (2008). Sex or gender? Expanding the sex-based view by introducing masculinity and femininity as predictors of financial risk taking. Journal of Economic Psychology, 29, 180-196. doi:10.1016/j.joep.2007.05.002

Nekby, L., Skogman Thoursie, P., \& Vahtrik, L. (2008). Gender and self-selection into a competitive environment: Are women more overconfident than men? Economics Letters, 100, 405-407. doi:10.1016/j.econlet.2008.03.005

Niederle, M., \& Vesterlund, L. (2007). Do women shy away from competition? Do men compete too much? The Quarterly Journal of Economics, 122, 1067-1101. doi:10.1162/qjec.122.3.1067

Ortmann, A., \& Tichy, L. (1999). Gender differences in the laboratory: Evidence from prisoner's dilemma games. Journal of Economic Behavior and Organization, 39, 327-339.
doi:10.1016/S0167-2681(99)00038-4

Palomino, F., \& Peyrache, E. A. (2010), Psychological bias and gender agwe gap. Journal of Economic Behavior \& Organization, 76, 563-573. doi:10.1016/j.jebo.2010.07.004

Soll, J,. \& Klayman, J. (2004). Overconfidence in interval estimates. Journal of Experimental Psychology: Learning, Memory, and Cognition, 20, 299-314. doi:10.1037/0278-7393.30.2.299

Svensson, O. (1981). Are we all less risky and more skillful than our fellow drivers? Acta Psychologica, 47, 143-148. doi:10.1016/0001-6918(81)90005-6

Tidemann, J. (2000). Parents' gender stereotypes and teachers' beliefs as predictors of children's concept of their mathematical ability in elementary school. Journal of Educational Psychology, 92, 144-151. doi:10.1037/0022-0663.92.1.144 